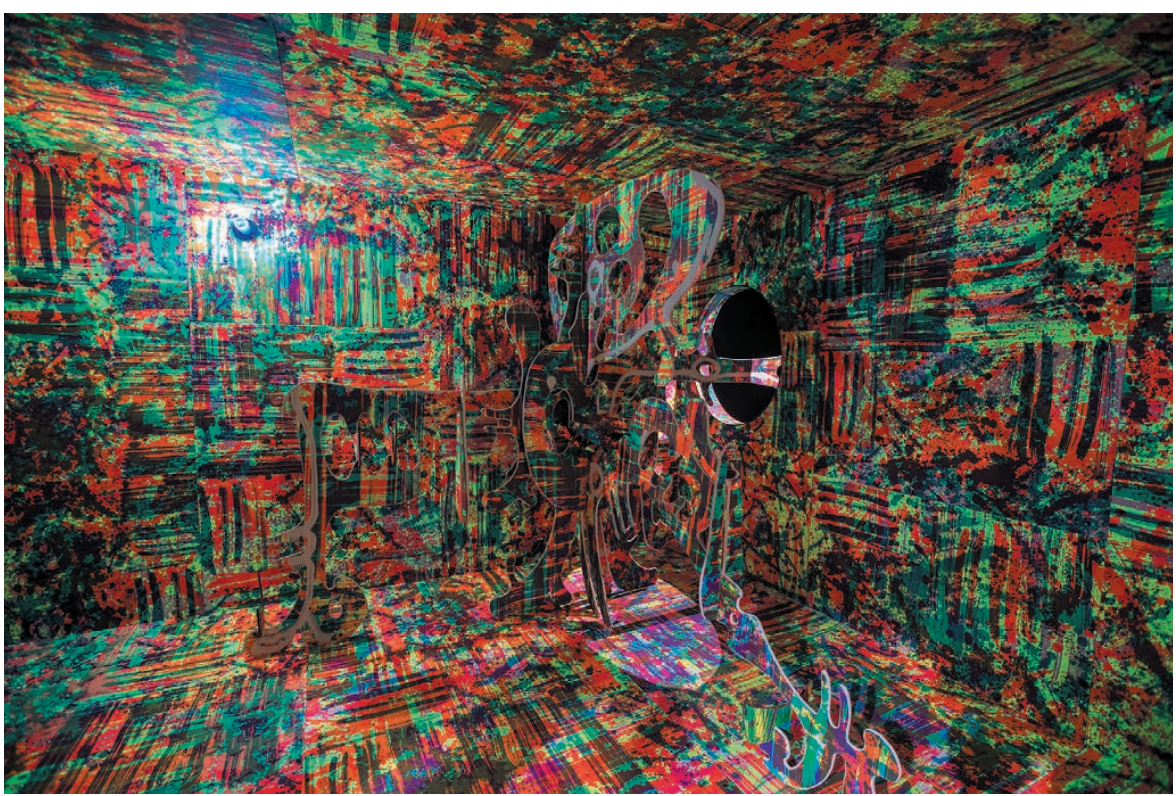

Daft Dank Space, a 2013 room installation by Aaron Curry, selected by neurobiologist Mark Changizi.

EVOLUTION

\title{
Four takes on the evolution of art
}

\section{Nurin Veis tours a show on theories of creativity, curated by a quartet of scientists.}

$\mathrm{P}$ ondering four nondescript doorways in a darkened entrance, I feel like a rat primed to hunt down cheese. But the quest laid out in On the Origin of Art, an exhibition at the Museum of Old and New Art (Mona) in Hobart, Australia, is to explore the labyrinthine journeys of four eminent scientist-curators. Each answers a tough question: does art have a biological basis, and has it contributed to human evolution?

The scientists are experimental psychologist Steven Pinker, evolutionary psychologist Geoffrey Miller, evolutionary theorist Brian Boyd and theoretical neurobiologist Mark Changizi. Each devoted two years to developing the show, collaborating with Mona curators. The exhibition aims to rip art-making and appreciation out of the realm of art historians, to probe whether there is a biological as well as a cultural premise to it.

Pinker, Miller, Boyd and Changizi selected works that reflect their own areas of expertise, producing four very separate journeys. The exhibition features 230 antiquities, photographs, paintings and contemporary installations spanning the Italian Renaissance,
On the Origin of Art Mona (Museum of Old and New Art), Hobart, Australia.

Until 17 April.

indigenous Australia and Ottoman Islam, among other cultures. There are dark, complex, twisting corridors bursting with lush pockets of art - and not a label in sight. Each scientist has recorded an audio tour for his segment, talking the visitor through the subtleties of their theories and selections. The result is a rich cacophony of intellectual and sensory delight.

The exhibition shows that art is a signalling system using patterns and pattern recognition for human communication. Pinker focuses on Darwinism, asking whether the desire and ability to make art is a heritable trait that gives humans a reproductive advantage, or whether it is a by-product of survival adaptations. He explores nature's patterns as biological cues for choice-making. As he shows through Aspassio Haronitaki's 2016 'flowerscape' Who Says Your Feelings Have to Make

We Share Our Chemistry with the Stars (AJ 280R) DIL2214, 2009, by Marc Quinn.
Sense, landscape paintings can elicit an aesthetic and emotional response to geography and, beyond that, to concepts of ideal habitats and survival.

Miller sees art as a strategy for attracting mates by signalling fitness, intelligence, skill, resourcefulness and dominance. One of his choices is Marc Quinn's 2009 We Share Our Chemistry with the Stars, which magnifies a human iris - a structure that both vividly displays interior emotion and receives others' signals.

Boyd suggests that art is cognitive play with pattern, a vehicle for processing human anxieties about existential uncertainty. Yayoi Kusama's room installation Dots Obsession Tasmania (2016) explores that liminal state through mirrors, a repetitive pattern of dots and amorphous shapes. Katsushika Hokusai's classic Great Wave off Kanagawa (around 1831) is a stylized, rhythmically controlled image of the dangerous natural world.

Changizi, meanwhile, argues that art mimics sounds and forms in nature, thus harnessing its patterns visually and aurally - but mainly as a way of connecting us emotionally. Changizi's selection, Daft Dank Space (2013) by Aaron Curry, is a riotously colourful room installation that echoes the interconnected organs and tissues in the human body. United Visual Artists' $440 \mathrm{~Hz}$ (2016) creates an alluring interactive installation that translates visitors' body movements into rhythms of light and sound.

The exhibition is more than the sum of its parts. Perhaps it is a little ambitious in applying reductionist scientific methodology to the complex realm of art-making and art appreciation. But it supports the idea that art is not purely a cultural phenomenon, but crosses diverse cultures with characteristic features such as depictions of land or human physiology. It highlights art as a vehicle for communication about fundamentals: procreation and survival, group identity, bonding and status. Museum director David Walsh acknowledges that the exhibition only touches on aspects of this expansive theme, stating that other perspectives remain to be explored. These include the role of folk art in community bonding, and the tactile process of making things that are valued and special, as has been described by researcher Ellen Dissanayake.

Jane Clark, senior research curator at Mona, hopes that the exhibition will promote openness to alternative ways of looking at and thinking about art. I found On the Origin of Art an exciting, highly stimulating, cross-disciplinary experience that delivers intellectual and sensory insights into how we make sense of our world. -

Nurin Veis is manager of Scienceworks, a science and technology museum in Melbourne, Australia.

e-mail:nveis@museum.vic.gov.au 